\title{
Impact of armed conflict on cardiovascular disease risk: a systematic review
}

\author{
Mohammed Jawad, ${ }^{\oplus 1}$ Eszter P Vamos, ${ }^{1}$ Muhammad Najim, ${ }^{1}$ Bayard Roberts, ${ }^{2}$ \\ Christopher Millett ${ }^{1}$
}

- Additional material is published online only. To view, please visit the journal online (http://dx.doi.org/10.1136/ heartjnl-2018-314459)

${ }^{1}$ Public Health Policy Evaluation Unit, Imperial College London School of Public Health, London, UK

2Department of Health Services Research and Policy, London School of Hygiene and Tropical Medicine, London, UK

\section{Correspondence to}

Dr Mohammed Jawad, Public Health Policy Evaluation Unit, Imperial College London School of Public Health, London W2 1PG, UK;

mohammed.jawad06@imperial. ac.uk

Received 12 November 2018 Revised 18 March 2019 Accepted 22 March 2019 Published Online First 28 May 2019

\section{ABSTRACT \\ Objectives Prolonged armed conflict may constrain efforts to address non-communicable disease in some settings. We assessed the impact of armed conflict on cardiovascular disease (CVD) risk among civilians in low/ middle-income countries (LMICs).}

Methods In February 2019, we performed a systematic review searching Medline, Embase, PsychINFO, Global Health and Web of Science without language or date restrictions. We included adult, civilian populations in LMICs. Outcomes included CVDs and diabetes, and eight clinical and behavioural factors (blood pressure, blood glucose, lipids, tobacco, alcohol, body mass index, nutrition, physical activity). We systematically reanalysed data from original papers and presented them descriptively.

Results Sixty-five studies analysed 23 conflicts, and $66 \%$ were of low quality. We found some evidence that armed conflict is associated with an increased coronary heart disease, cerebrovascular and endocrine diseases, in addition to increased blood pressure, lipids, alcohol and tobacco use. These associations were more consistent for mortality from chronic ischaemic heart disease or unspecified heart disease, systolic blood pressure and tobacco use. Associations between armed conflict and other outcomes showed no change, or had mixed or uncertain evidence. We found no clear patterning by conflict type, length of follow-up and study quality, nor strong evidence for publication bias.

Conclusions Armed conflict may exacerbate CVDs and their risk factors, but the current literature is somewhat inconsistent. Postconflict reconstruction efforts should deliver low-resource preventative interventions through primary care to prevent excess CVD-related morbidity and mortality.

PROSPERO registration number CRD42017065722

\section{INTRODUCTION}

Non-communicable diseases (NCDs), such as cardiovascular disease (CVD) and diabetes, are the leading cause of death and disability worldwide and are increasing in low/middle-income countries (LMICs). ${ }^{1}$ Target 3.4 of the Sustainable Development Goals is to reduce by one-third premature mortality from NCDs by 2030 and resolution WHA66.10 of the WHO includes a target to reduce by $25 \%$ premature mortality from NCDs by 2025 . The WHO recommends reaching this target by enhancing national capacity, strengthening health systems and creating health promoting environments.
One factor that may slow or reverse political and societal gains to meet these targets is the presence of armed conflict. According to the Uppsala Conflict Data Program, 73 armed conflicts were recorded globally in 2015, the highest on record, with these mainly occurring in LMICs. ${ }^{2}$ Increased military expenditure and political instability arising from conflict can weaken national infrastructures vital to health which in turn can alter the demand and supply of healthcare services. It can also discourage positive health behaviours through adverse stress-mediated coping mechanisms such as increased alcohol and tobacco use and the reduction in physical activity and consumption of healthy foods. ${ }^{3}$

Armed conflicts are no longer synonymous with high mortality rates from infectious disease epidemics and malnutrition. ${ }^{4}$ In addition to better control of infectious disease through vaccination, contemporary armed conflicts are characterised by low intensity, protracted duration, intrastate violence, internal displacement and ethnic rivalry, and now include a greater proportion of middle-income countries. ${ }^{4}$ In the context of an ageing population and a rising life expectancy at birth, it is therefore plausible that CVDs are the biggest contributor of excess deaths during armed conflict, rather than military violence and communicable diseases. $^{5}$

The effect of armed conflict on CVD and its risk factors has received a paucity of attention in the academic literature. ${ }^{67}$ This is disconcerting given that governments, humanitarian organisations and international agencies are challenged with how to effectively tackle CVDs during conflicts and into the postconflict setting. Better understanding around which components of CVD risk change during and after conflict can improve the preparation and implementation of evidence-based health systems interventions designed to address CVDs. Therefore, the aim of this study is to systematically review the literature to examine the impact of armed conflict on CVD and its risk factors among civilian populations in LMICs.

\section{METHODS}

This systematic review is registered on PROSPERO and follows the Preferred Reporting Items for Systematic Reviews and Meta-Analyses reporting standards. Our research question is: "What is the association between armed conflict and CVD risk for civilians in LMICs, compared to civilians with less or no exposure to armed conflict?' 


\section{Search strategy and selection criteria}

In February 2019, we searched Medline, Embase, PsychINFO, Global Health and Web of Science without language or date restrictions. We used synonyms and spelling variations of 'armed conflict' and combined these with our outcomes of interest (CVDs/diabetes, clinical and behavioural factors), and with LMIC countries (online supplementary file 1). In addition, we hand-searched citation lists of included studies to identify additional relevant articles. We requested unpublished data from corresponding authors of studies where appropriate, and we also contacted corresponding authors for studies which we could not acquire a full text. We did not search the grey literature as this yielded limited information on a preliminary search.

We included adult, civilian populations (including internally displaced persons and refugees) in LMICs exposed to author-defined armed conflict. Outcomes of interest were CVD and diabetes (categorised according to the International Classification of Disease, 10th Revision [ICD-10]), relevant clinical parameters (blood pressure, blood glucose, lipids) and key behavioural factors (tobacco use, alcohol use, body mass index [BMI], diet and physical activity). CVD categories used in this review included stroke, acute myocardial infarction, chronic ischaemic heart disease, ill-defined descriptions of heart disease, angina pectoris, other cardiac arrhythmias and other ischaemic heart disease.

We had no restrictions on quantitative study designs although to measure impact in a more robust manner they had to include a component of comparison, such as by time or inclusion of a conflict-unexposed group, in order to be eligible. We therefore included cross-sectional studies that used retrospective recall and self-reported changes in outcomes. For studies collecting serial data points during and after the conflict, we restricted studies to those with at least one measurement within 3 years of the end of the conflict given the unclear definition of 'postconflict'. ${ }^{3}$

We excluded studies reporting on military veterans, combatants, children, external migrants (eg, economic migrants) and refugees displaced to high-income countries. The latter was justified given that the vast majority of refugees live in LMICs, and available resources that shape cardiovascular health are very different to those in high-income countries.

\section{Data analysis}

Two reviewers screened in duplicate and independently the title and abstract of captured citations to identify potentially eligible studies. We retrieved full texts of studies considered potentially eligible by at least one reviewer. Two reviewers conducted a calibration exercise before screening in duplicate and independently the full texts, then abstracting data, using a standardised and pilot-tested screening form. They resolved disagreements by discussion, and when needed with the help of a third reviewer. Data abstraction details are found in online supplementary file 1.

Two reviewers used the Newcastle-Ottawa Scale (NOS) in duplicate and independently to conduct a quality assessment for each study. We scored cross-sectional and cohort studies out of eight, and case-control studies out of nine. Cohort studies are usually scored out of nine but the domain 'Was follow-up long enough for outcomes to occur?' was not relevant to our review so this was omitted. Although the NOS has no established threshold of quality, we defined studies of low quality as those that scored $<5$, those of moderate quality as those that scored 5 or 6 and those of high quality as those that scored 7 or more. We calculated mean quality scores by study design and year of publication, stratified by the domains of the NOS (selection, comparability and outcome).

We analysed data descriptively as conducting meta-analysis was not feasible given substantial heterogeneity between populations, armed conflicts, exposure ascertainment methods and outcome measures across studies. Given the varied statistical approach among included studies (including many where measures of precision were not reported and effect directions were not commented on by authors), we systematically reanalysed reported data. We ensured data from case-control studies were recalculated as ORs, and data from cross-sectional or cohort studies were recalculated as relative risks (for binary outcomes) and differences in means (for continuous outcomes). We ensured all effect estimates were presented with 95\% CIs and reported an effect direction (increasing, decreasing or no change) by considering CIs that did not overlap as statistically significant at an alpha level of 0.05 . We did not reanalyse data already presented as ORs, beta-coefficients or HRs.

To avoid weighted bias from studies that reported on the same outcome in multiple ways (eg, hypertension measured by both sphygmomanometer and self-report), we ensured no study contributed more than once to each outcome by selecting a single best outcome. This was done by abstracting the more valid measurement (eg, from medical records rather than self-report), followed by the one adjusted for more variables, then by the one presented as a continuous variable (eg, change in blood pressure) than categorical (eg, the prevalence of systolic blood pressure $\geq 140$ ). In studies where outcomes were reported only by population subgroups (eg, by age and sex), we combined stratified outcomes into an overall estimate, and used the overall outcome in our analysis. Finally, in studies that reported serial data before, during and after a conflict, we focused our analysis on outcomes that compared preconflict to during-conflict data.

We summarised the effect directions and study quality by broader-level outcomes, for example, CVDs (I00-159, I70-199), cerebrovascular diseases (I60-I69), endocrine diseases (E00E90), stratifying by incidence, prevalence or mortality where available. We then reported outcomes by the first level ICD-10 codes (eg, essential [primary] hypertension I10) using qualitative visualisations ('harvest plots'). These take aspects of a forest plot to display data on a matrix of effect direction weighted by several variables. ${ }^{8}$ The $\mathrm{x}$-axis for our harvest plots showed the effect direction (increase, decrease, no change), and the y-axis showed the study quality (NOS score). Each study was represented only once in each harvest plot. Among outcomes measured by at least three studies, consistency was considered present when at least $60 \%$ of studies were in one effect direction, with moderate-to-high quality studies being weighted double than that of low quality studies. We visually assessed publication bias by constructing an adapted funnel plot, using the sample size and effect direction in place of the SE and effect size, respectively.

\section{RESULTS}

\section{Description of included studies}

Of 149 potentially eligible studies, we excluded 84 mostly due to absence of a control group or only analysing one time point $(n=23)$, or having not defined armed conflict explicitly or at all $(n=19)$. Figure 1 shows the study flow and full details of study exclusions.

The included 65 studies analysed 23 armed conflicts; a summary of their characteristics and methodological quality are presented in table 1. A high proportion of studies had cross-sectional designs (56.9\%), most used control groups (61.5\%) rather 


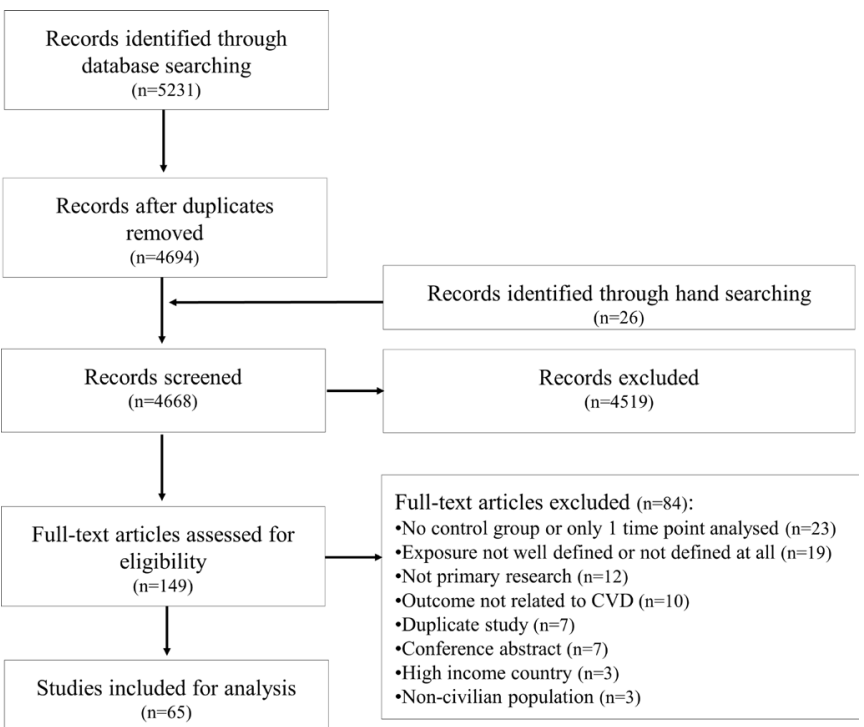

Figure 1 Study flow. CVD, cardiovascular disease.

than time trend analyses (38.5\%), and nearly half analysed either the Croatian War of Independence (1991-1995) (24.6\%) or the Bosnian War (1992-1995) (18.5\%). Most studies were conducted in community settings $(56.9 \%)$ and at the city level $(41.5 \%)$. Two-thirds $(66.2 \%)$ of studies were of low quality (score $<5$ ), 18.5\% were of moderate quality (score 5-6) and $15.4 \%$ were of high quality (score $>6$ ). No studies assessing temporal trends employed an interrupted time series or other quasi-experimental designs. The characteristics of individual studies are shown in online supplementary file 1 .

Table 2 reports mean quality scores by study design and year of publication, stratified by the three domains of the NOS (selection, comparability and outcome). In general, case-control studies scored the highest mean quality score (6.7/9; although only three were included) and ecological studies the lowest (1.1/8). Ecological studies, nearly all of which (84\%) assessed Croatian and Bosnian Wars of the 1990s, had lower mean quality scores in every domain compared with other study designs. Despite the generally low quality of included studies, there was a consistent stepwise increase in the mean quality score across all three domains and overall as the year of publication increased (eg, overall scores increased from 2.3 for studies published in 1999 or earlier, to 2.8 for studies published between 2000 and 2009, to 4.3 for studies published in 2010 or later).

\section{Summary of results}

Figure 2 presents the summary of results by broader-level outcomes and study quality. While results were somewhat inconsistent, some important patterns were noted. There was evidence from some studies that incidence and prevalence of coronary heart, cerebrovascular and endocrine diseases and mean blood pressure increased following exposure to armed conflict. For blood sugars and lipids, there was no consistent evidence of impact. For behavioural factors, there was evidence from some studies that alcohol use increased and consistent evidence that tobacco use increased following exposure to armed conflict. There was no evidence that armed conflict was associated with changes in BMI. This pattern remained relatively consistent when restricted to moderate-to-high quality studies, except in the case of lipids where more studies indicated increased lipid levels following exposure to armed conflict. Figure 2 is broken
Table 1 Study characteristics and methodological quality of 65 included studies

\begin{tabular}{|c|c|c|}
\hline Characteristic & & $\%$ (No) \\
\hline \multirow[t]{3}{*}{ Year of publication } & 1999 or earlier & $26.2(17)$ \\
\hline & 2000-2009 & $32.3(21)$ \\
\hline & 2010 or later & $41.5(27)$ \\
\hline \multirow[t]{3}{*}{ Funding source } & Reported & $40.0(26)$ \\
\hline & None declared & $6.2(4)$ \\
\hline & Not reported & $53.9(35)$ \\
\hline \multirow[t]{3}{*}{ Ethics approval } & Yes & $33.9(22)$ \\
\hline & 'Not required' & $3.1(2)$ \\
\hline & Not reported & $63.1(41)$ \\
\hline \multirow[t]{4}{*}{ Study design } & Cross-sectional & $47.7(31)$ \\
\hline & Ecological & $29.2(19)$ \\
\hline & Cohort & $18.5(12)$ \\
\hline & Case-control & $4.6(3)$ \\
\hline \multirow[t]{10}{*}{ Armed conflict } & Croatian War of Independence (1991-1995) & $24.6(16)$ \\
\hline & Bosnian War (1992-1995) & $18.5(12)$ \\
\hline & Colombian conflict (1975-2015) & $9.2(6)$ \\
\hline & Siege of Leningrad (1941-1944) & $7.7(5)$ \\
\hline & Lebanese Civil War (1975-1991) & $6.2(4)$ \\
\hline & Georgian-Ossetian Conflict (1989-present) & $3.1(2)$ \\
\hline & US-led invasion of Iraq (2003-2011) & $3.1(2)$ \\
\hline & Sudan Civil War (1983-2015) & $3.1(2)$ \\
\hline & Unspecific conflicts in Uganda & $3.1(2)$ \\
\hline & Other conflicts & $21.5(14)$ \\
\hline \multirow[t]{5}{*}{ Level of jurisdiction } & City & $41.5(27)$ \\
\hline & Subnational & $26.2(17)$ \\
\hline & National & $23.1(15)$ \\
\hline & Camp or village & $7.7(5)$ \\
\hline & Not reported & $1.5(1)$ \\
\hline \multirow[t]{4}{*}{ Setting } & Community & $56.9(37)$ \\
\hline & Hospital & $38.5(25)$ \\
\hline & Educational establishment & $1.5(1)$ \\
\hline & Not reported & $3.1(2)$ \\
\hline \multirow[t]{6}{*}{$\begin{array}{l}\text { Armed conflict exposure } \\
\text { measurement }\end{array}$} & $\begin{array}{l}\text { Uniform exposure to all based on time and } \\
\text { place }\end{array}$ & $47.7(31)$ \\
\hline & Exposure to specific armed conflict events & $20.0(13)$ \\
\hline & Exposure based on time of birth & $12.3(8)$ \\
\hline & Exposure based on internal displacement & $9.2(6)$ \\
\hline & $\begin{array}{l}\text { Exposure based on war-related post- } \\
\text { traumatic stress disorder }\end{array}$ & $4.6(3)$ \\
\hline & Other exposure & $3.0(2)$ \\
\hline \multirow[t]{2}{*}{ Comparison type } & Control group & $61.5(40)$ \\
\hline & Time trend & $38.5(25)$ \\
\hline \multirow{4}{*}{$\begin{array}{l}\text { Time between conflict and } \\
\text { outcome }\end{array}$} & Less than 5 years & $27.7(18)$ \\
\hline & 5.0-9.9years & $23.1(15)$ \\
\hline & 10.0-39.9years & $27.7(18)$ \\
\hline & 40 years or more & $21.5(14)$ \\
\hline \multirow[t]{3}{*}{ Newcastle-Ottawa Scale } & Low quality (score <5) & $66.2(43)$ \\
\hline & Moderate quality (score 5-6) & $18.5(12)$ \\
\hline & High quality (score $>6$ ) & $15.4(10)$ \\
\hline
\end{tabular}

down further by figures 3-5 which show the summary of results by individual-level outcomes.

\section{Individual outcomes}

See online supplementary file 2 presents the summary of 22 individual outcomes with at least three studies, stratified by quality to provide a better indication of the consistency of findings (ie, $>60 \%$ of studies suggesting an effect direction). No outcome 


\begin{tabular}{|c|c|c|c|c|}
\hline & $\begin{array}{l}\text { Selection } \\
\text { (maximum 4) }\end{array}$ & $\begin{array}{l}\text { Comparability } \\
\text { (maximum 2) }\end{array}$ & $\begin{array}{l}\text { Outcome } \\
\text { (maximum 2) }\end{array}$ & $\begin{array}{l}\text { Total } \\
\text { (maximum 8) }\end{array}$ \\
\hline \multicolumn{5}{|l|}{ Study design } \\
\hline Cross-sectional & $2.1(1.0)$ & $0.9(1.0)$ & $0.9(0.6)$ & $3.9(1.6)$ \\
\hline Ecological & $0.4(1.0)$ & $0.0(0.0)$ & $0.6(0.5)$ & $1.1(1.2)$ \\
\hline Cohort & $2.7(0.8)$ & $0.6(0.9)$ & $1.2(0.6)$ & $4.4(1.2)$ \\
\hline Case-control & $2.3(0.6)$ & $1.3(1.2)$ & $2.0(0.0)^{*}$ & $6.7(1.5) \dagger$ \\
\hline \multicolumn{5}{|l|}{ Year of publication } \\
\hline 1999 or earlier & $1.2(1.3)$ & $0.2(0.7)$ & $0.8(0.8)$ & $2.3(2.6)$ \\
\hline 2000-2009 & $1.5(1.5)$ & $0.3(0.7)$ & $0.9(0.5)$ & $2.8(1.9)$ \\
\hline 2010 or later & $2.2(0.9)$ & $1.1(1.0)$ & $1.0(0.6)$ & $4.3(1.4)$ \\
\hline
\end{tabular}

was shown to consistently decrease following exposure to armed conflict. Outcomes assessing mortality from chronic ischaemic heart disease (ICD-10 code I25; 3 studies), ${ }^{9-11}$ mortality from unspecified heart disease (I51; 5 studies), ${ }^{9}{ }^{12-15}$ systolic blood pressure (8 studies) $)^{9-1116-20}$ and tobacco use (11 studies) ${ }^{21-31}$ had consistent evidence of an increase following exposure to armed conflict.

Nine outcomes assessed showed consistent evidence of no change following exposure to armed conflict. These included four diseases (acute myocardial infarction [I21; 7 studies], ${ }^{32-38}$ angina pectoris [I20; 5 studies], ${ }^{19}{ }^{33-36}$ chronic ischaemic heart disease [I25; 4 studies], ${ }^{10} 181939$ mortality from unspecified stroke [I64; 4 studies]), ${ }_{10} 111440$ three clinical factors (fasting blood glucose [6 studies], ${ }^{17-19} 214142$ haemoglobin A1c [HbA1c] [3 studies], ${ }^{174142}$ total cholesterol [7 studies] $)^{917-19294142}$ and two behavioural factors (BMI [11 studies], ${ }^{91017-19244143-46}$ overweight [5 studies]). ${ }^{10} 16172447$

Nine outcomes assessed showed inconsistent evidence of change following exposure to armed conflict. These included four diseases (essential hypertension [110; 12 studies], unspecified heart disease [151; 5 studies], unspecified stroke [I64; 5 studies], unspecified diabetes mellitus [E14; 11 studies]), three clinical factors (diastolic blood pressure [8 studies], high-density lipoprotein [3 studies], triglycerides [9 studies]) and two behavioural factors (alcohol [16 studies], obesity [7 studies]) (see online supplementary file 1 for citations).

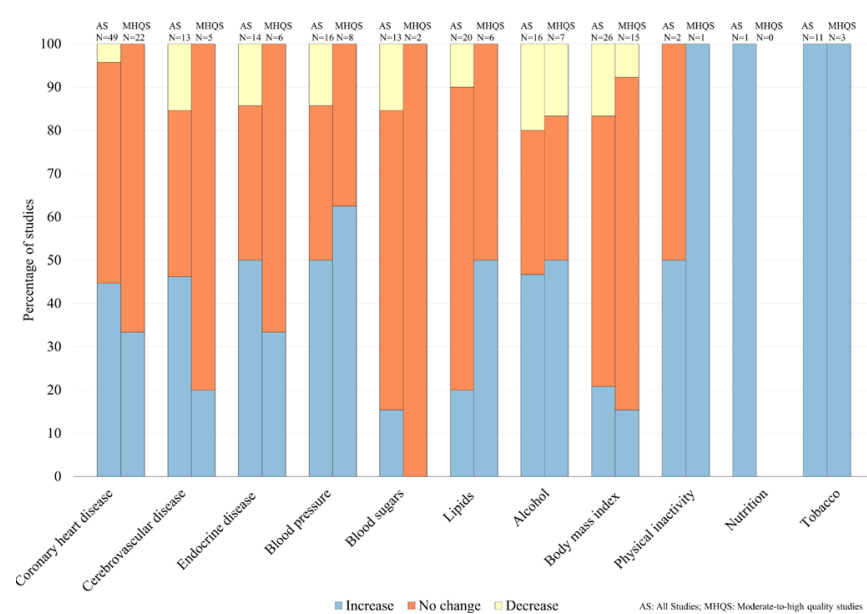

Figure 2 Exposure to armed conflict and non-communicable disease risk—summary of results by broader-level outcomes. Solid colour: all studies; patterned colour: moderate-to-high quality studies; $n=$ number of studies.

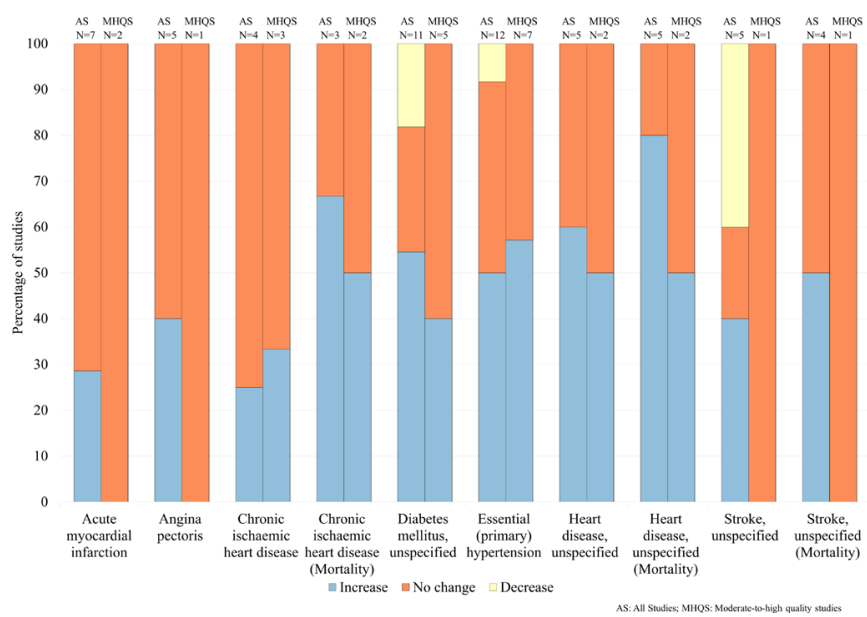

Figure 3 Exposure to armed conflict and non-communicable diseases-summary of results by individual-level outcomes. Solid colour: all studies; patterned colour: moderate-to-high quality studies; $\mathrm{n}=$ number of studies.

A further 19 outcomes had inadequate evidence ( $<3$ studies per outcome) for an assessment of the impact of armed conflict. These included a range of CVDs, impaired glucose tolerance, low-density lipoprotein, access to iodised salt, underweight and physical inactivity (see online supplementary file 1 for citations).

Data on individual-level outcomes are expanded on in harvest plots, shown in online supplementary file 2 , in order to reveal patterns by study quality, study type, length of follow-up and armed conflict type. We found no obvious patterns by these factors due to the low number of studies in each outcome.

\section{Publication bias}

Figure 6 shows an adapted funnel plot to assess publication bias, which includes all outcomes from all studies. While the absence of actual effect estimates limits interpretation, the plot does not present convincing evidence of asymmetry or the absence of small studies showing no effect, which are indicative of publication bias.

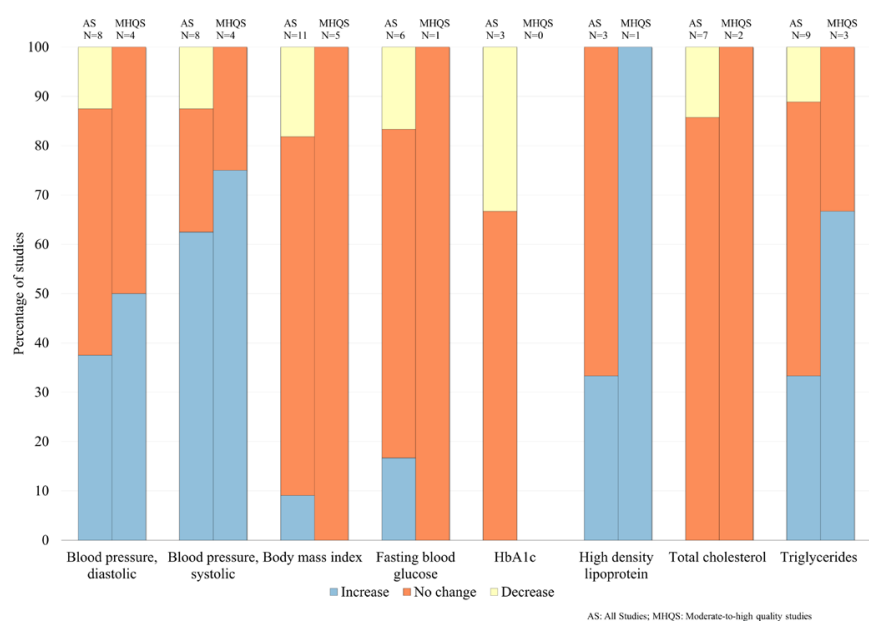

Figure 4 Exposure to armed conflict and non-communicable disease clinical factors-summary of results by individual-level outcomes. Solid colour: all studies; patterned colour: moderate-to-high quality studies; $\mathrm{n}=$ number of studies. 


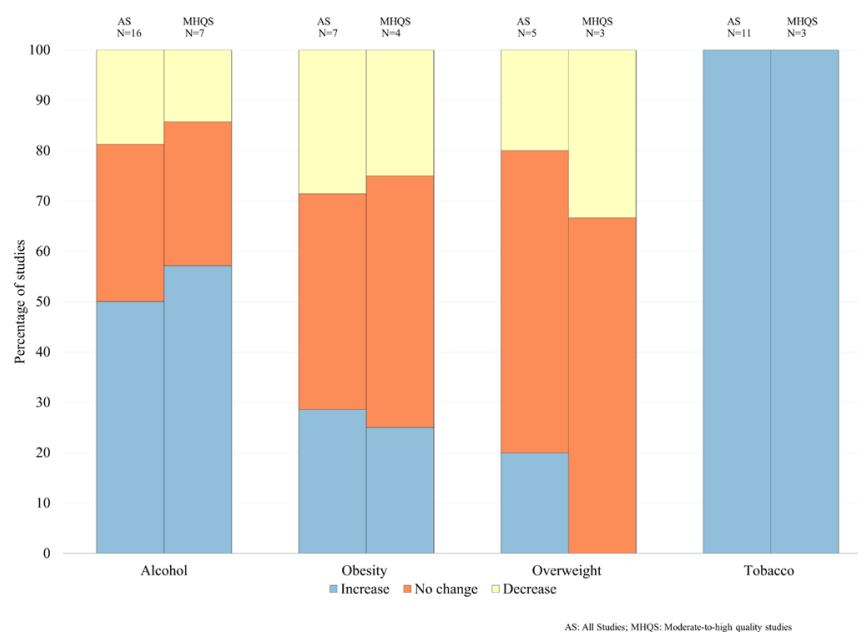

Figure 5 Exposure to armed conflict and non-communicable disease behavioural factors - summary of results by individual-level outcomes. Solid colour: all studies; patterned colour: moderate-to-high quality studies; $\mathrm{n}=$ number of studies.

\section{DISCUSSION}

This review found some evidence that armed conflict is associated with increased coronary heart disease, cerebrovascular disease and endocrine disease, in addition to increased blood pressure levels, alcohol and tobacco use. Associations were more consistent for mortality from chronic ischaemic heart disease or unspecified heart disease, systolic blood pressure and tobacco use. Evidence for a link between armed conflict and other outcomes remains absent, uncertain or inadequate. Inferences are limited by the small number and low quality of included studies, the wide range of reported outcomes and methods of assessment. Associations between armed conflict and some outcomes were inconsistent (eg, CVD outcomes, figure 3). The explanation for this inconsistency is unclear given the underlying causal pathways are conceptually similar (eg, stress-induced or disruption of disease prevention programmes) but may reflect methodological shortcomings and the low number of studies for some outcomes. Some results should therefore be interpreted with caution until better designed research are performed. However, both the number and quality of studies examining the relationship between armed conflict and CVD has increased in recent years.

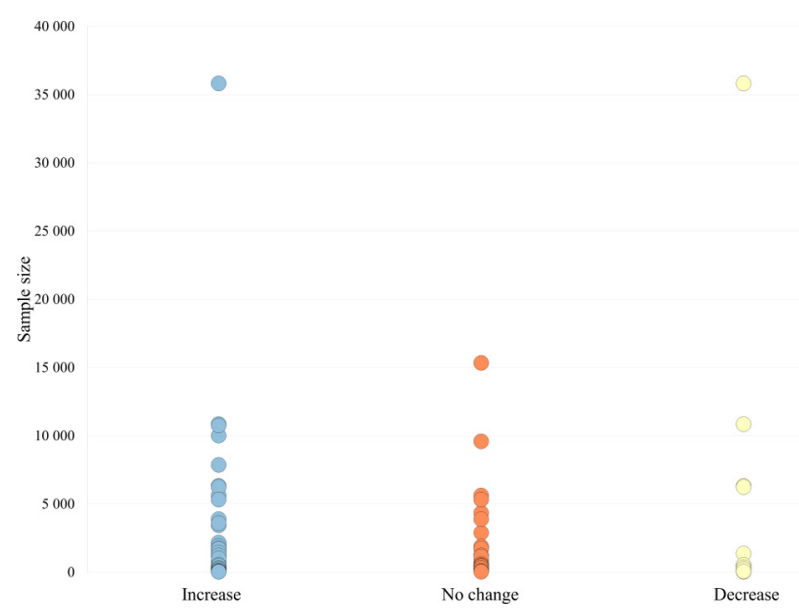

Figure 6 Adapted funnel plot assessing publication bias.
Our findings show that patterning of associations by conflict type, length of follow-up and study quality are unclear. Differential effects by conflict type may reflect underlying methods of warfare, for example, siege tactics affecting BMI more than aerial bombardment, in addition to the baseline health system performance and the health status of the underlying population. These stratifications are important and may serve as confounding variables in the association between armed conflict and CVD and should be incorporated into the study designs of future work.

Included studies did not provide sufficient detail to understand causal pathways between armed conflict and CVD risk, such as the deterioration of risk factors at population level or changes in the clinical management of high-risk individuals. However, the increase in blood pressure, tobacco and alcohol use identified following exposure to armed conflict has important implications. Previous work suggests that these risk factors may be sensitive to exposure to armed conflict ${ }^{67}$ and they are leading risk factors in the global disease burden. ${ }^{1}$ The explanation of this finding is likely to be complex and multifactorial, possibly driven by a stress response and change in health behaviours at the individual level and disruptions to healthcare provision at the population level. Notably, tobacco industries are often among the first to establish themselves in postconflict settings which is a cause for concern when rebuilding conflict-affected areas. ${ }^{3}$ Previous research suggests a positive association between stress and the development of type 2 diabetes mellitus ${ }^{48}$ and poor glycaemic control, ${ }^{49}$ and reduced healthcare access during times of armed conflict could exacerbate this association further, but our review did not find enough evidence to corroborate this link.

The research literature on the association between armed conflict and CVD and its clinical and behavioural factors is skewed towards three main conflicts (the Bosnian War, Croatian War of Independence and the Colombian Civil War). The almost complete lack of attention given to conflicts within the Middle East is of concern given that it remains the world's least peaceful region. There is a research need for further studies on the impact of armed conflict on nutrition and physical activity, in addition to better examining the link between stress and CVD and its risk factors among conflict-affected populations. We identified only one study which examined the impact of armed conflict on CVD risk among refugees (rather than among civilians who remained in conflict-affected settings, including internally displaced persons). ${ }^{47}$ Other potentially eligible studies conducted among refugees were excluded because there was no component of comparison. The lack of studies is concerning given the recent rise in refugee movements worldwide and the need to understand the double burden of armed conflict and forced migration. Future study designs should prioritise the use of control groups, capture outcomes using validated tools and adequately address confounding, but the need to balance feasibility against robustness and costs is an important consideration in conflict settings. Quasi-experimental approaches such as an interrupted time series should also be considered, especially if routine health data are collected by health services or local organisations. Other methodological advancements could include improved data on specific conflict-related events, linking survey data to local health registries and propensity score matching on key variables. The complete absence of studies using interrupted time series designs is reflected in the low quality of ecological studies.

How to best address the rising prevalence of CVD in LMICs in the context of armed conflict through a combination of whole population and high-risk interventions needs greater policy focus. Primary healthcare is a central tenet to deliver CVD preventative interventions but is underprioritised in low-resource 
settings and may be especially vulnerable for disruption during armed conflict. The WHO Package of Essential Non-communicable Disease Interventions could be usefully adapted to address this vulnerability and identify whether and how primary carebased 'best buys' can be delivered in conflict and postconflict settings. ${ }^{50}$ Training healthcare professionals to deliver interventions during and postconflict and ensuring continuity in the supply of common medications are key priorities. The underdiagnosis and underrecording of CVD and their risk factors during times of conflict should also be considered in the health system planning of conflict-affected settings. It is prudent for future studies to examine access to, and effectiveness of, CVD-related services, particularly at the primary care level.

To the best of our knowledge, this is the first systematic review to examine the impact of armed conflict on CVD and its risk factors, and highlights clear research gaps that should guide future work. The systematic reanalysis of included studies has enabled the extraction and reporting of associations not adequately presented in the original papers, and ensured both the direction and precision of each effect estimate are captured. This review is limited by the small number of studies that are mainly low quality, the inability to formally assess publication bias, the use of scoring for risk of bias assessments and that the majority of evidence arises from a handful of conflicts. This may limit the generalisability of this review and the strength of its conclusions. The relationship between armed conflict and health remains complex and multifactorial, and homogenising armed conflict as a simplistic exposure variable has its limitations. As more studies address CVD and armed conflict, a sensitivity analysis by sex and age may be insightful to determine whether there are differential effects by population subgroups.

To conclude, armed conflict may be associated with increased mortality from stroke and heart disease, increased blood pressure levels and increased tobacco use in the populations they affect, though the strength of evidence is limited by low study

\section{Key messages}

What is already known on this subject?

- Civilians from low/middle-income countries (LMICs) are disproportionately affected by cardiovascular disease (CVD).

- Most armed conflicts occur in LMICs.

- Protracted armed conflict may exacerbate CVD risk.

What might this study add?

- This is the first systematic review to assess the association between armed conflict and CVD risk.

- We assessed 65 studies and 23 armed conflicts, and found evidence that armed conflict is associated with increased coronary heart disease, cerebrovascular and endocrine diseases, in addition to increased blood pressure, lipids, alcohol and tobacco use.

- This risk may manifest itself during periods of active conflict, but also in the acute and chronic postconflict period.

\section{How might this impact on clinical practice?}

- Whole population and high-risk interventions need greater policy attention in settings affected by armed conflict.

- Primary care may be best positioned to deliver such interventions.

- Training of healthcare professionals is required to deliver CVD prevention and control measures in the postconflict period. quality. There is an urgent need to expand research in this area to better inform how governments and agencies can best respond to reduce the burden of CVDs in conflict and postconflict settings.

Acknowledgements MJ is supported by the Medical Research Council Doctoral Training Partnership. The Public Health Policy Evaluation Unit is supported by the National Institute for Health Research School of Public Health Research.

Contributors Study conception and design: MJ, EPV, BR and CM. Acquisition of data: MJ and MN. Analysis and interpretation of data: MJ, MN and EPV. Drafting of manuscript: MJ. Critical revision: EPV, BR, MN and CM.

Funding The authors have not declared a specific grant for this research from any funding agency in the public, commercial or not-for-profit sectors.

Competing interests None declared.

Patient consent for publication Not required.

Provenance and peer review Not commissioned; externally peer reviewed.

Data sharing statement All data are provided in the supplementary files.

\section{REFERENCES}

1 Kontis V, Mathers CD, Rehm J, et al. Contribution of six risk factors to achieving the $25 \times 25$ non-communicable disease mortality reduction target: a modelling study. Lancet 2014;384:427-37.

2 UCDP. Uppsala Conflict Data Program. Department of Peace and Conflict Research [online]. https://bit.ly/2L1TBkx (access 16 May 2018).

3 Roberts B, Patel P, McKee M. Noncommunicable diseases and post-conflict countries. Bull World Health Organ 2012;90:2-2A.

4 Spiegel PB, Checchi F, Colombo S, et al. Health-care needs of people affected by conflict: future trends and changing frameworks. Lancet 2010;375:341-5.

5 Spiegel PB, Salama P. War and mortality in Kosovo, 1998-99: an epidemiological testimony. Lancet 2000;355:2204-9.

6 Lo J, Patel P, Roberts B. A systematic review on tobacco use among civilian populations affected by armed conflict. Tob Control 2016;25 2129140.

7 Lo J, Patel P, Shultz JM, et al. A Systematic Review on Harmful Alcohol Use Among Civilian Populations Affected by Armed Conflict in Low- and Middle-Income Countries. Subst Use Misuse 2017;52:1494-510.

8 Ogilvie D, Fayter D, Petticrew M, et al. The harvest plot: a method for synthesising evidence about the differential effects of interventions. BMC Med Res Methodol 2008:8:8.

9 Alajbegović S, Ž M, Alajbegović A, et al. Cigarette smoking, alcohol consumption, overweight and obesity in diabetic and nondiabetic patients with acute myocardial infarction. Diabetologia Croatica 2002;31:223-9.

10 Bergovec M, Heim I, Vasilj I, et al. Acute coronary syndrome and the 1992-1995 war in Bosnia and Herzegovina: a 10-year retrospective study. Mil Med 2005;170:431-4.

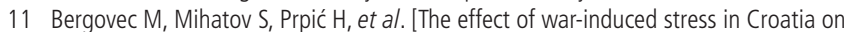
the incidence and mortality of acute ischemic heart disease]. Wien Med Wochenschr 1992:142:430-2.

12 Dumitrascu DL, Hopulele S, Baban A. Cardiovascular complaints following the uprising of December 1989 in Romania. Med War 1993;9:45-51.

13 Mihatov S, Bergovec M, Prpić $\mathrm{H}$, et al. Incidence and hospital mortality of acute coronary artery disease among civilians in Zagreb during air-raid alarms. Acta Med Croatica 1995;49:49-52.

14 Mirić D, Giunio L, Bozić l, et al. Trends in myocardial infarction in Middle Dalmatia during the war in Croatia. Mil Med 2001;166:419-21.

15 Rumboldt Z, Giunio L, Miric D, et al. War-stress-induced medical emergencies in south Croatia. Lancet 1993:341:965-6.

16 Stanner SA, Yudkin JS. Fetal programming and the Leningrad Siege study. Twin Res 2001:4:287-92.

17 Sparén $P$, Vågerö $D$, Shestov $D B$, et al. Long term mortality after severe starvation during the siege of Leningrad: prospective cohort study. BMJ 2004;328:11.

18 Rotar O, Moguchaia E, Boyarinova M, et al. Seventy years after the siege of Leningrad: does early life famine still affect cardiovascular risk and aging? J Hypertens 2015:33:1772-9.

19 Sibai AM, Armenian HK, Alam S. Wartime determinants of arteriographically confirmed coronary artery disease in Beirut. Am J Epidemiol 1989;130:623-31.

20 Vågerö D, Koupil I, Parfenova N, et al. Long term health consequences following the Siege of Leningrad. Early Life Nutrition and Adult Health and Development 2013:207-25.

21 Vaktskjold A, Yaghi M, Balawi U, et al. The mortality in Gaza in July-September 2014: a retrospective chart-review study. Confl Health 2016;10:10.

22 Dimitrijević J, Dzirlo K, Bratić M, et al. [10-year analysis of cerebrovascular accidents at the Neurology Clinic in Sarajevo (before, during and after the war)]. Med Arh 2002; $56: 151-3$. 
23 Kulenovic I, Robertson A, Grujic M, et al. The impact of war on Sarajevans with non-insulin-dependent diabetes mellitus. The European Journal of Public Health 1996:6:252-6.

24 Babić $R$, Maslov B, Babić $D$, et al. The prevalence of metabolic syndrome in patient with posttraumatic stress disorder. Psychiatr Danub 2013;25(Suppl 1):45-50.

25 Pibernik-Okanović M, Roglić G, Prasek M, et al. War-induced prolonged stress and metabolic control in type 2 diabetic patients. Psychol Med 1993;23:645-51.

26 Roglic G, Metelko Z. Effect of war on glycemic control in type II diabetic patients. Diabetes Care 1993;16:806-8.

27 Koupil I, Shestov DB, Sparén P, et al. Blood pressure, hypertension and mortality from circulatory disease in men and women who survived the siege of Leningrad. Eur J Epidemiol 2007;22:223-34

28 Santić Z, Lukić A, Sesar D, et al. Long-term follow-up of blood pressure in family members of soldiers killed during the war in Bosnia and Herzegovina. Croat Med J 2006:47:416-23.

29 Ghazanfari Z, Ghazanfari T, Araghizadeh H, et al. Physical activity of the civilian chemical victims of Sardasht 20 years after sulfur mustard exposure. Toxin Rev 2009;28:48-53.

30 Grimard F, Laszlo S. Long-Term Effects of Civil Conflict on Women's Health Outcomes in Peru. World Dev 2014;54:139-55.

31 McNabb SJ, Welch K, Laumark S, et al. Population-based nutritional risk survey of pensioners in Yerevan, Armenia. Am J Prev Med 1994;10:65-70.

32 Robertson A, Fronczak N, Jaganjac N, et al. Nutrition and immunization survey of Bosnian women and children during 1993. Int J Epidemiol 1995:24:1163-70.

33 Vespa J, Watson F. Who is nutritionally vulnerable in Bosnia-Hercegovina? BMJ 1995:311:652-4.

34 Hult M, Tornhammar P, Ueda P, et al. Hypertension, diabetes and overweight: looming legacies of the Biafran famine. PLoS One 2010;5:e13582.

35 Delbiso TD, Rodriguez-Llanes JM, Altare C, et al. Health at the borders: Bayesian multilevel analysis of women's malnutrition determinants in Ethiopia. Glob Health Action 2016;9:30204.

36 Surwit RS, Schneider MS, Feinglos MN. Stress and diabetes mellitus. Diabetes Care 1992:15:1413-22.
37 Rosenzweig S, Reibel DK, Greeson JM, et al. Mindfulness-based stress reduction is associated with improved glycemic control in type 2 diabetes mellitus: a pilot study. Altern Ther Health Med 2007;13:36.

38 World Health Organisation. Package of Essential Noncommunicable (PEN) Disease Interventions for Primary Health Care. http://bit.ly/1RONegW (Accessed 06.10.15).

39 Hagopian A, Flaxman AD, Takaro TK, et al. Mortality in Iraq associated with the 2003-2011 war and occupation: findings from a national cluster sample survey by the university collaborative Iraq Mortality Study. PLoS Med 2013;10:e1001533.

40 Sibai AM, Fletcher A, Armenian HK. Variations in the impact of long-term wartime stressors on mortality among the middle-aged and older population in Beirut, Lebanon, 1983--1993. Am J Epidemiol 2001;154:128-37.

41 Roberts L, Lafta R, Garfield R, et al. Mortality before and after the 2003 invasion of Iraq: cluster sample survey. The Lancet 2004;364:1857-64.

42 Obilom RE, Thacher TD. Posttraumatic stress disorder following ethnoreligious conflict in Jos, Nigeria. J Interpers Violence 2008:23:1108-19.

43 Creson D, Schmitz JM, Arnoutović A. War-related changes in cigarette smoking: a survey study of health professionals in Sarajevo. Subst Use Misuse 1996;31:639-46.

44 Creson D, Schmitz JM, Smitran M. War related changes in cigarette smoking: a followup survey study of health professionals in Sarajevo. J Subst Use 1999:4:239-41.

45 Gómez-Restrepo C, Tamayo-Martínez N, Buitrago G, et al. [Violence due to Armed Conflict and Prevalence of Mood Disorders, Anxiety and Mental Problems in the Colombian Adult Population]. Rev Colomb Psiquiatr 2016;45(Suppl 1):147-53.

46 Idris A, Al Saadi T, Turk T, et al. Smoking behaviour and patterns among university students during the Syrian crisis. East Mediterr Health J 2018:24:154-60.

47 Kadojić $D$, Demarin $V$, Kadojić $M$, et al. Influence of prolonged stress on risk factors for cerebrovascular disease. Coll Antropol 1999;23:213-9.

48 Roberts B, Chikovani I, Makhashvili N, et al. Tobacco use and nicotine dependence among conflict-affected men in the Republic of Georgia. Int J Environ Res Public Health 2013;10:2185-97.

49 Sokolova-Djokic L, Zizic-Borjanovic S, Igic R. Cigarette smoking in Serbia. Impact of the 78-day NATO bombing campaign. J Buon 2008;13:285-9.

50 Farhood LF, Chaaya M, Saab BR. Detainment and health: the case of the Lebanese hostages of war. Int J Ment Health Nurs 2010;19:83-91. 